\title{
In vitro Antimicrobial Assay of Actinomycetes in Rice Against Xanthomonas oryzae pv. oryzicola and as Potential Plant Growth Promoter
}

\author{
Erneeza Mohd Hata ${ }^{1 *}$ Kamaruzaman Sijam $^{1}$, Zainal Abidin Mior Ahmad ${ }^{1}$, Mohd Termizi \\ Yusof $^{2}$ and Noor Aisyah Azman ${ }^{1}$ \\ ${ }^{I}$ Department of Plant Protection; Faculty of Agriculture; Universiti Putra Malaysia; Serdang, Selangor - Malaysia. \\ ${ }^{2}$ Department of Microbiology; Faculty of Biotechnology and Biomolecular Sciences; Universiti Putra Malaysia; \\ Serdang, Selangor - Malaysia
}

\begin{abstract}
The aim of this work was to in vitro assay the antimicrobial activity of actinomycetes in rice against Xanthomonas oryzae pv. oryzicola and as potential plant growth promoter. A total of 92 actinomycete strains were isolated from different rice plant components and field locations. Of these, only $21.74 \%$ showed antagonistic activity against the Xoc pathogen. Molecular identification via $16 \mathrm{~s}$ rRNA amplification revealed that $60 \%$ of the active antagonistic strains belonged to the genus Streptomyces. Isolates that demonstrated the highest antagonistic activity were also able to produce hydrolytic enzymes and plant growth-promoting hormones. Combination of preliminary screening based on in vitro antagonistic, hydrolytic enzyme and plant growth hormone activity facilitated the best selection of actinomycete candidates as evidenced by strains classification using cluster analysis (Ward's Method). Results from the preliminary screening showed that actinomycetes, especially Streptomycetes, could offer a promising source for both biocontrol and plant growth-promotion agents against BLS disease in rice.
\end{abstract}

Key words: antagonistic activity, hydrolytic enzyme, plant growth-promoting agent, Streptomyces

\section{INTRODUCTION}

Actinomycetes are abundantly distributed from 10 to $50 \%$ of soil microflora community (Alexander 1997) with the possibility of producing 10-20 secondary metabolites for each actinomycete strain (Bentley et al. 2002; Arasu et al. 2009). Actinomycetes receive a wide attention due to their potential as producers of a large number of useful and diverse function bioactive secondary metabolites such as antibiotics and extracellular enzymes (Inbar et al. 2005; El-Tarabily and Sivasithamparam 2006). Actinomycetes have been associated as biocontrol agent in several studies against plant pathogenic fungi and pathogenic bacteria (Hasegawa et al. 2006; Baltz 2008; Loqman et al. 2009; Oskay 2009). Apart from that, actinomycetes are also able to promote plant growth by the production of phytohormone and indole acetic acid compound (Hamdali et al. 2008). However, potential of actinomycetes as plant growth promoter has been poorly investigated despite of their abundance population in soil microflora (Doumbou 2001).

Cultivation of resistant varieties is one of the options to overcome disease emergence but resistant varieties are susceptible to the disease within consecutive years of application (Ouhdouch

*Author for correspondence: erneeza@yahoo.com 
et al. 2001). Other issues related to excessive dependency on chemical pesticides, which frequently contribute to environmental pollution and human health problems. Therefore, natural or biological control has received increased attention because it provides an environmentally friendly, long-lasting, inexpensive and safe alternative for control of plant diseases (Aghighi et al. 2004). Within the same context of safe food and environment obligation as well as cost wise, the use of plant growth-promoting agent to improve plant growth is an alternative for reducing chemical inputs in agriculture (Saharan and Nehra 2011).

Potential of actinomycetes to be developed as biocontrol agent is mainly indicated by antibiosis, lysis mechanism, plant systemic resistance stimulation and plant growth promoter substances (Berg and Hallmann 2006). Biocontrol agent, which may function as plant growth-promoting agent at the same time stimulate plant growth directly by altering plant hormone levels, facilitating iron acquisition via siderophore production, fixing atmospheric nitrogen and solubilising minerals for plant uptake (Lugtenberg and Kamilova 2009). Utilization of actinomycete strains with biocontrol and plant growthpromoting characteristics in biofertilizers and biocontrol products are the best approach, which facilitate in sustainable plant cultivation (Verma et al. 2011).

Cutting-edge research on biocontrol and agents for pathogenic Xanthomonas spp. within different hosts has focused on the use of plant-associated bacteria, especially Pseudomonas fluorescens and different strains of Bacillus spp. (Velusamy and Gnanamanickam 2003; Kloepper et al. 2004; Dutta et al. 2005). X. oryzae pv. oryzicola (Xoc) is the causal pathogen for Bacterial Leaf Streak (BLS) disease, which is one of the important diseases in the tropical and sub-tropical rice cultivation areas of Asia (Xie and Mew 1998; Chen et al. 2006). BLS is prevalent in Asia and certain regions of Africa, where the yield loss can reach up to $17 \%$, depending on the rice variety and climatic conditions (Wang et al. 2007). To-date, no reports are available on the efficacy of actinomycetes against $X o c$ in rice. Preliminary screening via in vitro assay is important as initial step in selecting the best actinomycetes with multi beneficial attributes as plant growth regulators and biocontrol agent properties. Therefore, the aim of this study was to isolate, screen and characterize plant growth and biocontrol traits of actinomycete strains capable of antagonising Xoc pathogen via in vitro assay.

\section{MATERIAL AND METHODS}

\section{Isolation of actinomycetes}

A total of 92 actinomycetes with different morphological distinctions were collected from the soils, rhizosphere and internal roots of rice plants obtained from different rice cultivation areas of Tanjung Karang, Semerak and Kuala Muda in Malaysia from August 2013 to June 2014. Isolation of actinomycetes was performed according to each type of sample: i) for soil, $10 \mathrm{~g}$ of soil was mixed with $90 \mathrm{~mL}$ of sterile distilled water; ii) for the rhizosphere, 2-5 g of rhizosphere was mixed with $95 \mathrm{~mL}$ of sterile distilled water; iii) for internal roots, 2-5 g of rhizosphere samples was surface sterilised, and roots were meshed with mortar and pestle and mixed with $95 \mathrm{~mL}$ of sterile distilled water; iv) for healthy leaves (free from disease symptoms), 2-5 $\mathrm{g}$ of healthy leaf samples was fragmented to a length of 2-cm and surface sterilised, and sterile leaves were mashed with a mortar and pestle and mixed with $95 \mathrm{~mL}$ of sterile distilled water. All mixtures of samples were homogenised and shaken in an incubator shaker at $180 \mathrm{rpm}$ for 20 minutes. Next, serial dilutions of each sample suspension were inoculated on Actinomycetes Isolation Agar (AIA, Difco) using the spread plate method and incubated at $28^{\circ} \mathrm{C}$ for seven days. The AIA medium was supplemented with $40 \mu \mathrm{g} / \mathrm{mL}$ of cyclohexamide to inhibit fungal growth and $10 \mu \mathrm{g} / \mathrm{mL}$ of nalidixic acid to inhibit other bacterial growth without affecting the actinomycetes (Loqman et al. 2009). Pure cultures were obtained by sub-culturing and were stored in $20 \%$ glycerol at $-80^{\circ} \mathrm{C}$ for long-term preservation.

\section{Antibacterial activity against Xanthomonas oryzae pv. oryzicola (Xoc)}

The bacterium used for this study, Xanthomonas oryzae pv oryzicola (Xoc), was isolated and characterised via biochemical and molecular methods, including pathogenicity testing prior to further analysis of antibacterial activity. Purified Xoc culture was inoculated in Peptone Sucrose Broth (PSB) supplemented with cyclohexamide $(0.05 \mathrm{~g} / \mathrm{L})$, cephalexin $(0.04 \mathrm{~g} / \mathrm{L})$ and kasugamycin $(0.02 \mathrm{~g} / \mathrm{L})$ and incubated at $28^{\circ} \mathrm{C}$ for three days. Then, the test pathogens were diluted with sterile distilled water and the concentration was adjusted 
to approximately $10^{7}-10^{8} \mathrm{CFU} / \mathrm{mL}$ using a spectrophotometer at a $660 \mathrm{~nm}$ wavelength. Pure actinomycete culture was inoculated vertically at the centre of Yeast Malt (YM), agar with $5 \mathrm{~mm}$ length and incubated at $30^{\circ} \mathrm{C}$ for seven days.

The growing actinomycetes were killed by inverting the plates over chloroform for three min (Lemessa and Zeller 2007). Next, plates with grown actinomycetes were flooded with $2.0 \mathrm{~mL}$ of previously prepared pathogen suspension, air dried and incubated for 2-3 days. The antibacterial activity that indicated antagonistic results was measured by subtracting actinomycetes colony growth length at the centre plate from the combined inhibition zone length and actinomycete colony growth length. The experiments were conducted using a completely randomised design with three replications.

\section{In vitro screening of hydrolytic enzyme production}

Active antagonistic actinomycetes were selected from the previous experiment and evaluated for hydrolytic enzyme and plant growth-promoting activities. Actinomycete isolates were inoculated in $\mathrm{YM}$ broth at $30^{\circ} \mathrm{C}$. After seven days, concentration of actinomycete in YM broth were adjusted to $10^{8} \mathrm{CFU} / \mathrm{mL}$ and were spot inoculated $(10 \mu \mathrm{L})$ onto specific media plates for each enzyme determination (amylase, protease, cellulolytic and lipase). All diameters that indicated positive results were measured by subtracting the actinomycete colony diameter from the combined positive zone diameter and the actinomycete colony diameter.

\section{Amylase enzyme}

For amylase enzyme detection, starch agar was prepared using peptone $(5.0 \mathrm{~g} / \mathrm{L})$, beef extract $(3.0$ $\mathrm{g} / \mathrm{L})$, soluble starch $(2.0 \mathrm{~g} / \mathrm{L})$ and agar $(16 \mathrm{~g} / \mathrm{L})$. Isolate suspensions were inoculated onto starch agar and incubated at $30^{\circ} \mathrm{C}$ for seven days. Plates were flooded with iodine solution and the diameters of positive results were measured by the non-blue surrounding growth.

\section{Protease enzyme}

Protease detection was performed using skim milk agar (Difco). The diameter of a positive reaction was measured by the appearance of a clear zone surrounding the actinomycete growth on skim milk agar after seven days of incubation at $30^{\circ} \mathrm{C}$.

\section{Cellulase enzyme}

Cellulolytic enzyme production was measured using carboxymethyl cellulose (CMC) agar. The medium was prepared using CMC $(5.0 \mathrm{~g} / \mathrm{L})$, $\mathrm{Na}_{2} \mathrm{HPO}_{4}(6.0 \mathrm{~g} / \mathrm{L}),\left(\mathrm{NH}_{4}\right)_{2} \mathrm{SO}_{4}(4.0 \mathrm{~g} / \mathrm{L})$, yeast extract $(1.0 \mathrm{~g} / \mathrm{L}), \mathrm{MgSO}_{4} .7 \mathrm{H}_{2} \mathrm{O}(0.2 \mathrm{~g} / \mathrm{L})$ and agar $(15 \mathrm{~g} / \mathrm{L})$. The result was visualised by flooding the seven-day grown actinomycete plates with $0.1 \%$ Congo Red solution for $15 \mathrm{~min}$ and washing with $1 \mathrm{M} \mathrm{NaCl}$. The diameter of the clear zone surrounding the colonies on CMC agar was measured.

\section{Lipase enzyme}

The agar medium for lipase enzyme production was prepared with slight modifications (Silfkin 2000). The medium consisted of peptone (10.0 $\mathrm{g} / \mathrm{L}), \mathrm{NaCl}(5.0 \mathrm{~g} / \mathrm{L}), \mathrm{CaCl}_{2}(0.1 \mathrm{~g} / \mathrm{L})$ and agar $(15.0 \mathrm{~g} / \mathrm{L})$ with the $\mathrm{pH}$ adjusted to 6.8 . The medium was sterilised and cooled at $50^{\circ} \mathrm{C}$ and supplemented with sterile Tween $20 \quad(0.5 \%$ concentration of final volume). Actinomycetes were inoculated in agar plates, incubated at $30^{\circ} \mathrm{C}$, and examined daily for 10 days. The diameter of soluble crystals surrounding the inoculation site was measured for positive lipase production.

\section{In vitro screening of plant growth-promoting (PGP) activities}

Plant growth activities (phosphate solubilisation, hydrogen cyanide production, siderophore production, nitrogen fixation activity and phytohormone production) were screened for all the active antagonistic actinomycetes. Actinomycete isolates were inoculated in $\mathrm{YM}$ medium broth for seven days at $30^{\circ} \mathrm{C}$ and inoculated in the specific media plates for each plant-growth activity determination. All diameters that indicated positive results were measured by subtracting the actinomycete colony diameter from the combined positive zone diameter and the actinomycete colony diameter. Hydrogen cyanide and nitrogen fixation ability were observed based on a qualitative scale.

\section{Phosphate solubilisation}

Isolates were spot inoculated on Pikovskaya's agar consisting of yeast extract $(0.5 \mathrm{~g} / \mathrm{L})$, dextrose $(10$ $\mathrm{g} / \mathrm{L}), \mathrm{Ca}_{3}\left(\mathrm{PO}_{4}\right)_{2}(5.0 \mathrm{~g} / \mathrm{L}),\left(\mathrm{NH}_{4}\right)_{3} \mathrm{PO}_{4}(0.5 \mathrm{~g} / \mathrm{L})$, $\mathrm{KCl}(0.2 \mathrm{~g} / \mathrm{L}), \mathrm{MgSO}_{4} \cdot 7 \mathrm{H}_{2} \mathrm{O}(0.1 \mathrm{~g} / \mathrm{L}), \mathrm{Mn}\left(\mathrm{SO}_{4}\right)_{2}$ $(0.0001 \mathrm{~g} / \mathrm{L}), \mathrm{FeSO}_{4}(0.0001 \mathrm{~g} / \mathrm{L})$, and agar $(17$ $\mathrm{g} / \mathrm{L})$. The $\mathrm{pH}$ value of the medium was adjusted to 7.0 prior to sterilisation. The inoculated plates 
were incubated at $30^{\circ} \mathrm{C}$ for $7-10$ days. The appearance of a halo around the soluble growth suggested phosphate solubilisation activity and the halo was measured.

\section{Hydrogen cyanide (HCN)}

Hydrogen cyanide $(\mathrm{HCN})$ production tests were performed in Tryptone Soy Agar (TSA) supplemented with $4.4 \mathrm{~g} / \mathrm{L}$ of glycine. Actinomycete cultures were streaked on the entire plate and placed on Whatman No. 1 filter paper (previously impregnated with picric acid solution) on the lid of the petri dish. Inoculated plates with the picric acid solution filter papers were sealed properly and incubated at $30^{\circ} \mathrm{C}$ for $5-7$ days. A positive reaction for in vitro $\mathrm{HCN}$ production was indicated by qualitative observation of changes in the filter paper colour from yellow to orangebrown.

\section{Siderophore production}

Siderophore production of actinomycetes was screened on Chrome azurol S (CAS) agar medium as described by Mahmoud and Abd-Alla (2001). The diameter of the yellow halo surrounding the actinomycete growth was measured and indicated a positive CAS reaction.

\section{Nitrogen fixation}

Nitrogen fixation ability was tested by growing the isolates in nitrogen-free (NF) medium as described by Eskew et al. (1977) with slight modification. The composition of the NF medium was as follows (g/L): DL-malic acid (5.0), $\mathrm{K}_{2} \mathrm{HPO}_{4}(0.5)$, $\mathrm{MgSO}_{4} .7 \mathrm{H}_{2} \mathrm{O}(0.2), \mathrm{KOH}(4.0), \mathrm{NaCl}(0.1), \mathrm{CaCl}_{2}$ (0.02), $0.5 \%$ bromothymol blue in $0.2 \mathrm{M} \mathrm{KOH}$ solution $(2.0 \mathrm{~mL}), 1.64 \%$ FeEDTA solution $(4.0$ $\mathrm{mL})$, sterile filtered vitamin solution $(1.0 \mathrm{~mL})$ and sterile filtered micronutrient solution $(2.0 \mathrm{~mL})$. The $\mathrm{pH}$ was adjusted to 6.5 and $18.0 \mathrm{~g}$ agar was added to the final volume. Vitamin solution composition was as follows: biotin $(0.01 \mathrm{~g})$ and pyridoxine $(0.02 \mathrm{~g})$ in $0.1 \mathrm{~L}$ distilled water. The micronutrient solution consisted of $\mathrm{Na}_{2} \mathrm{MoO}_{4}(0.2$ g), $\mathrm{MnSO}_{4} \cdot \mathrm{H}_{2} \mathrm{O}(0.235 \mathrm{~g}), \mathrm{H}_{2} \mathrm{BO}_{3}(0.28 \mathrm{~g})$, $\mathrm{CuSO}_{4} .5 \mathrm{H}_{2} \mathrm{O}(0.008 \mathrm{~g})$ and $\mathrm{ZnSO}_{4} .7 \mathrm{H}_{2} \mathrm{O}(0.024 \mathrm{~g})$ in $0.2 \mathrm{~L}$ distilled water. The inoculated plates were incubated for seven days at $30^{\circ} \mathrm{C}$. The isolates' ability to fix $\mathrm{N}_{2}$ was observed from qualitative observation of blue coloration surrounding the growth.

\section{Indole acetic acid (IAA)}

Production of phytohormone or indole acetic acid (IAA) was determined according to Kaur et al. (2013). Actinomycetes from YM agar (7-day incubation period) were inoculated in YM broth supplemented with $0.2 \%$ L-tryptophan. The broth was incubated in an incubator shaker at $30^{\circ} \mathrm{C}$ for seven days with $180 \mathrm{x} g$ shaking. The broth was centrifuged at $10,0000 \mathrm{~g}$ for 10 minutes, and 1.0 $\mathrm{mL}$ of supernatant was collected. Salkowski reagent $\left(1.0 \mathrm{~mL}\right.$ of $0.5 \mathrm{M} \mathrm{FeCl}_{3}$ in $50 \mathrm{~mL}$ of $35 \%$ $\mathrm{HClO}_{4}$ ) was added to the supernatant at a ratio of 2:1 and incubated at room temperature for $25 \mathrm{~min}$. Development of a pink colour indicated the IAA production, and determination was performed using a spectrophotometer at $535 \mathrm{~nm}$. The IAA production from each isolate was compared with the IAA standard and a standard curve was prepared using different concentrations of pure IAA $(0,1,2,3,4,5,6,7,8,9$ and $10 \mathrm{mg}$ of IAA $/ \mathrm{mL}$ ). The supernatant from uninoculated test tubes in which no visible colour was observed, was used as a control.

\section{Identification of potential actinomycete strains using molecular identification}

Genotypic characterisation of active antagonistic actinomycetes was performed using 16s rRNA amplification with the universal primer $8 \mathrm{~F}$ (5'AGAGTTTGATCCTGGCTCAG3') and the 1492R (5'GGTTACCTTGTTACGACTT3') primer pair synthesised by Integrated DNA Technologies (IDT), Singapore. Genomic DNA was extracted using the Genomic DNA Mini Kit (GeneAid). The PCR reaction mixture $(50 \mu \mathrm{L})$ consisted of $1.0 \mu \mathrm{L}$ of forward primer, $1.0 \mu \mathrm{L}$ of reverse primer, $25 \mu \mathrm{L}$ of DreamTaq Green Mastermix (Thermo Scientific), $6.0 \mu \mathrm{L}$ of template DNA and $8.5 \mu \mathrm{L}$ of nuclease-free water. The PCR reactions were performed in a thermal cycler (MJ Mini Personal Thermal Cycler, Bio-Rad) with the following procedure: initial denaturation at $95^{\circ} \mathrm{C}$ for $3 \mathrm{~min}$; 35 cycles of denaturation $(1 \mathrm{~min}$ at $\left.95^{\circ} \mathrm{C}\right)$, annealing $\left(1 \mathrm{~min}\right.$ at $\left.57^{\circ} \mathrm{C}\right)$ and extension $(1$ min at $72^{\circ} \mathrm{C}$ ); and finally, final extension at $72^{\circ} \mathrm{C}$ for $10 \mathrm{~min}$ (Turner et al. 1999). Amplified PCR products $(5 \mu \mathrm{L})$ were fractionated in $1 \%$ agarose in $1 \mathrm{x}$ TAE. Gels were stained with FluoroSafe DNA Stain $\left(1^{\text {st }}\right.$ Base $)$ and photographed under UV light $(312 \mathrm{~nm})$. The PCR products were purified using the Qiaquick PCR Purification Kit (Qiagen, Hilden, Germany) and outsourced to $1^{\text {st }}$ Base Sdn. Bhd. for sequencing. The sequence data were 
aligned and identified using the Basic Local Alignment Search Tool in BLAST (NCBI, USA). Identified sequence alignments were compared with the NCBI GenBank database.

\section{Statistical analysis}

Experiments were conducted using Completely Randomised Design (CRD) for actinomycete population, antibacterial activity, hydrolytic enzyme production and plant growth-promoting activities (siderophore and phosphate solubilisation) for quantification analysis. Data collection was subjected to the analysis of variance and means were compared using the Least Significant Difference (LSD) test at the 0.05 probability level. A distance matrix for different antagonistic actinomycetes was analysed using Ward's minimum variance in the PROC CLUSTER procedure of the SAS 9.3 software (SAS Institute Inc.). A distance matrix was constructed based on quantitative and qualitative data from hydrolytic enzyme and plant growth analysis.

\section{RESULTS AND DISCUSSION}

\section{Actinomycete population and isolation}

This study was conducted to highlight the presence of actinomycetes in the rice field ecosystem and characterise the strains that produced antagonistic activity against Xoc. Significant differences were observed in the population of actinomycetes recovered from different rice varieties, plant ages and sampling locations (Table 1). Rice cultivar MR253 at the flowering growth stage showed higher actinomycete populations compared with those of MR219 at the maximum tilling stage, except for the rhizosphere sample. The actinomycete population in the rhizosphere ranged from $93.09 \times 10^{3} \mathrm{CFU} / \mathrm{g}$ to $359.60 \times 10^{3} \mathrm{CFU} / \mathrm{g}$, and the highest value was recorded in the MR219 variety at the maximum tilling growth stage. Endophytic actinomycetes from the roots and shoots showed the lowest population $(\mathrm{p}<0.05)$ in every sampling location compared with those of soil samples and the rhizosphere. The highest number of actinomycetes was isolated from the Tanjung Karang, Selangor rice field area. A total of 92 isolates were obtained from this study and were isolated from different sources, i.e., 39 soils, 42 rhizospheres, eight endophytic roots and three endophytic leaves (Table 2). Separation of actinomycete isolates was performed based on such morphological characteristics as colony colour, margin of colony, colony surface, aerial mycelium and substrate mycelium.

The highest actinomycete population was recorded from the rhizosphere compared with other samples or plant components. Continuous supply of beneficial substrates derived from the plant roots exudation provides a beneficial nutrient to microorganism population in rhizosphere soil.The plant rhizosphere provides a dynamic ecosystem that influences microbial activity, structure and diversity through root exudation (Grayston et al. 1996; Garbeva et al. 2008). The rhizosphere at the maximum tillering stage actively supported plant growth compared with the flowering stage, during which growth was slightly static. Plant cultivars and growth stages are also significant determinants of microbial community development in the soils (Naher et al. 2009).

\section{Antimicrobial activities against pathogenic Xanthomonas oryzae pv. oryzicola.}

All the 92 actinomycete isolates were screened for antagonistic activity as indicated by clear zone production on the media inoculated with Xoc (Fig. 1). A total of 20 actinomycete strains demonstrated antagonistic activity against Xoc, as shown in Figure 2, which represented only $21.74 \%$ of the total isolated strains. Other isolates demonstrated no antimicrobial activity against Xoc via this method. Most of the active antagonistic strains were isolated from the rhizosphere (35\%), followed by the soils $(30 \%)$, internal roots $(25 \%)$ and leaves (20\%). The inhibition zone (subtraction of actinomycete colony growth length at the centre plate from combined length of inhibition zone and actinomycete growth), which represented a positive result for antagonism, ranged from 2.00 $\mathrm{mm}$ to $17.67 \mathrm{~mm}$. Isolate SS8 from the rhizosphere in the Tanjung Karang rice field showed the highest antagonistic activity $(\mathrm{p}<0.05)$ compared with other active isolates.

Screening for the antibacterial activity against pathogens is an essential step for preliminary assessment of the antibacterial effects of potential isolates for further studies. In this study, the chloroform vapour method successfully ascertained the antibacterial activity of actinomycetes against Xoc, and the same method was used in previous study to assess the antibacterial activity of Streptomyces setoni, Bacillus subtilis and fluorescent pseudomonads 
against the plant pathogen Ralstonia solanacearum (Lemessa and Zeller 2007). Based on this study, the chloroform vapour method was capable of producing a clear inhibition zone for preliminary assessment of antibacterial and antagonistic activity.

Table 1 - Actinomycete population in soils, rhizosphere, roots and leaves from different locations, rice varieties and plant growth stages.

\begin{tabular}{llcccccc}
\hline \multicolumn{1}{c}{ Location } & Plant & Rice & Soil & \multicolumn{4}{c}{ Actinomycete population (10 $\left.\mathbf{1 0}^{\mathbf{3}} \mathbf{c f u} / \mathbf{g}\right)$} \\
\cline { 6 - 8 } & Growth & Variety & $\mathbf{p H}$ & Soil & Rhizosphere & Internal Roots & Healthy Leaves \\
\hline Tanjung Karang & Maximum & MR219 & 4.95 & $150.32^{\mathrm{bB}}$ & $359.60^{\mathrm{aA}}$ & $3.24^{\mathrm{bcB}}$ & $0.11^{\mathrm{cB}}$ \\
& tilling & & & & & & \\
Semerak & Flowering & MR253 & 3.37 & $47.20^{\mathrm{bC}}$ & $93.09^{\mathrm{aB}}$ & $4.77^{\mathrm{cB}}$ & $0.56^{\mathrm{cA}}$ \\
Gong Manak & Flowering & MR253 & 3.92 & $260.67^{\mathrm{aA}}$ & $175.03^{\mathrm{bB}}$ & $14.81^{\mathrm{cA}}$ & $0.79^{\mathrm{cA}}$ \\
\hline
\end{tabular}

All tests were performed in triplicate, and the results were averaged. The means in a - row followed by different lower case letters are significantly different (LSD $\alpha=0.05$ ) based on sample source/plant components. The means in a - column followed by different upper case letters are significantly different (LSD $\alpha=0.05$ ) based on sampling locations.

Table 2 - Rhizospheric and endophytic classification and distribution of actinomycete isolates from different locations and isolation sources.

\begin{tabular}{lclcc}
\hline Location & Plant variety & Isolation source & Number of isolates & Percentage \\
\hline Tanjung Karang, Selangor & MR219 & Soil & 14 & 38.89 \\
& & Rhizosphere & 18 & 50.00 \\
& & Internal root & 3 & 8.33 \\
& & Healthy leave & 1 & 2.78 \\
\hline \multirow{2}{*}{ Semerak, Kelantan } & Total isolates & & 36 & 100.00 \\
& MR253 & Soil & 12 & 40.00 \\
& & Rhizosphere & 15 & 50.00 \\
& & Internal root & 2 & 6.67 \\
\hline Gong Manak, Kelantan & Total isolates & Healthy leave & 1 & 3.33 \\
\hline & MR253 & Soil & 30 & 100.00 \\
\hline & & Rhizosphere & 13 & 50.00 \\
& & Internal root & 9 & 34.62 \\
& & Healthy leave & 3 & 11.54 \\
\hline
\end{tabular}
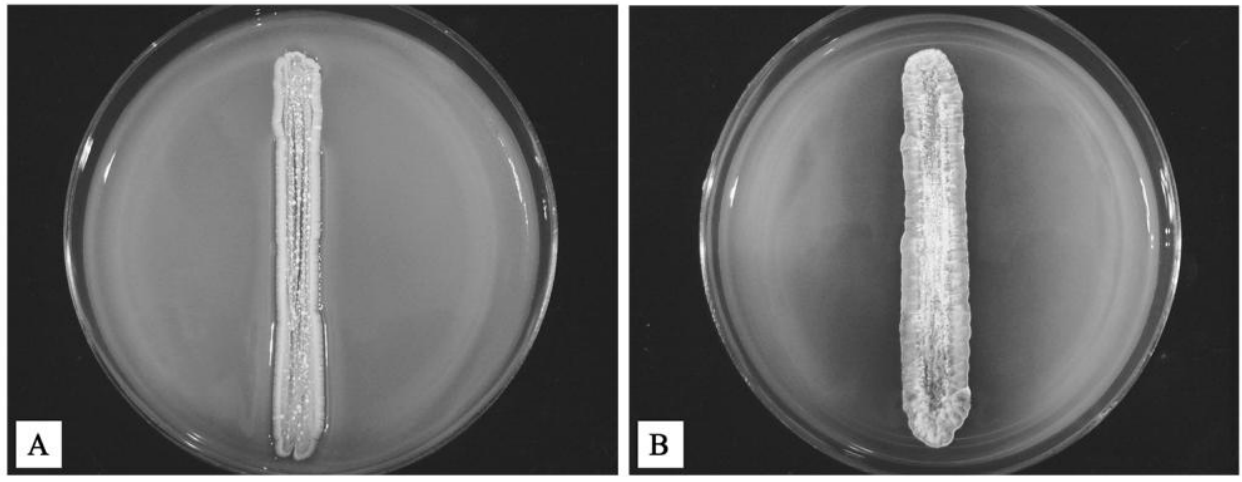

Figure 1 - Antagonistic activity using the chloroform vapour method: A) No antagonistic activity was observed on YM agar. B) Antagonistic activity was evaluated by measuring the inhibition zone around antagonistic actinomycetes. 


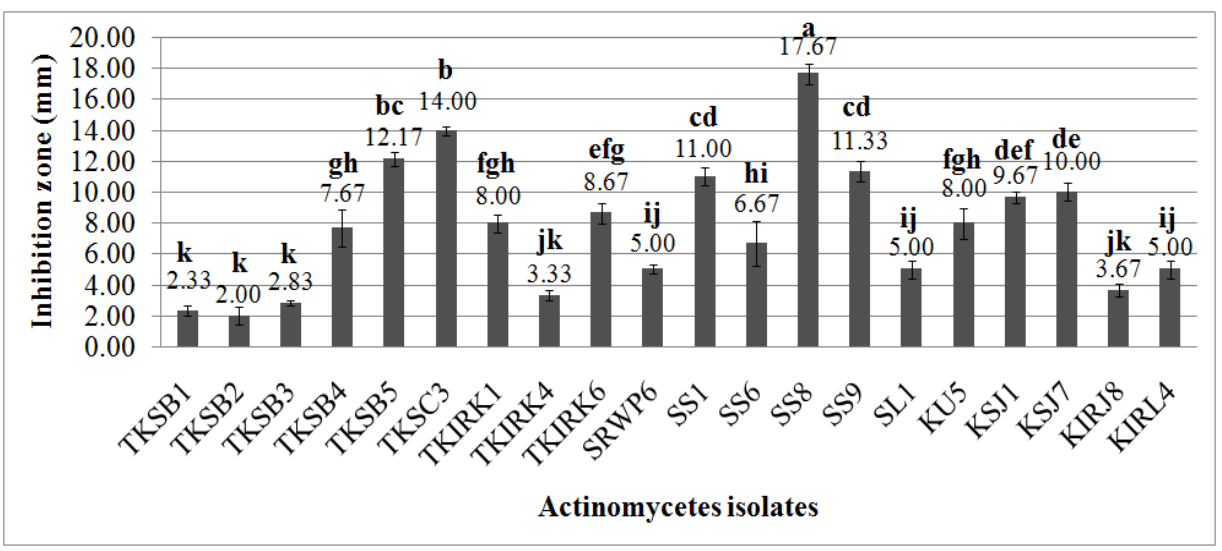

Figure 2 - In vitro antibacterial activities of active actinomycetes against Xanthomonas oryzae $p v$. oryzicola $(X o c)$. All tests were performed in triplicate, and the results were averaged. The means with the same letter are not significantly different (LSD $\alpha=0.05$ ).

\section{Identification of actinomycetes using a molecular method}

All the active antagonistic isolates were subjected to 16s rRNA amplification for actinomycete identification. All the isolates were successfully amplified and produced DNA fragment sizes of approximately 1450 bp. The antagonistic actinomycetes were successfully amplified by $16 \mathrm{~s}$
rRNA amplification (Table 3). Sixty percent of a total of 20 isolates were homologically similar to various species under the Streptomyces genus available in the GenBank database. Other potential actinomycetes were identified under the genera Nocardia (15\%), Microbacterium (10\%), Tsukamurella (5\%), Pseudonocardiaceae (5\%) and Amycolatopsis (5\%).

Table 3 - Molecular identification of potential actinomycetes by 16s rRNA gene amplification.

\begin{tabular}{lllcc}
\hline \multicolumn{1}{c}{ Isolate } & $\begin{array}{c}\text { Source of } \\
\text { isolation }\end{array}$ & \multicolumn{1}{c}{ Closest relative in NCBI } & $\begin{array}{c}\text { NCBI accession } \\
\text { number }\end{array}$ & $\begin{array}{c}\text { Sequence } \\
\text { similarity } \%\end{array}$ \\
\hline TKSB1 & Soil & Microbacterium oxydans strain JN44 & KJ850325.1 & 100 \\
TKSB2 & Soil & Nocardia nova strain SBP 20/14 & KP792981 & 100 \\
TKSB3 & Soil & Nocardia niigatensis strain PB-32 & KP792982 & 100 \\
SRWP6 & Soil & Microbacterium sp. FeL27 & KP792996 & 99 \\
SS1 & Soil & Streptomyces gancidicus & KP792994 & 99 \\
KU5 & Soil & Pseudonocardiaceae bacterium NH3 & KP861908 & 99 \\
TKSB4 & Rhizosphere & Streptomyces sp. T1 & KP792993 & 100 \\
TKSB5 & Rhizosphere & Streptomyces koyangensis strain B025 & KP792983 & 99 \\
TKSC3 & Rhizosphere & Streptomyces shenzhenensis strain 116-2 & KP792984 & 99 \\
SS6 & Rhizopshere & Streptomyces chartreusis strain AAS2 & KP792987 & 100 \\
SS8 & Rhizopshere & Streptomyces sp. SW4-2s & KP792988 & 99 \\
SS9 & Rhizopshere & Streptomyces hygroscopicus strain FoRh4 & KP792989 & 100 \\
KSJ1 & Rhizosphere & Amycolatopsis methanolica 239 & KP843724 & 100 \\
TKIRK1 & Internal root & Streptomyces sp. ICBB 8198 & KP792985 & 99 \\
TKIRK4 & Internal root & Streptomyces sp. 13-33-9 & KP792995 & 100 \\
TKIRK6 & Internal root & Streptomyces sp. TL7 & KP792986 & 99 \\
KSJ7 & Internal root & Streptomyces sp. TY40-3 & KP792991 & 100 \\
KIRJ8 & Internal root & Nocardia cyriacigeorgica & KP792997 & 99 \\
SL1 & Leaf & Tsukamurella sp. H404 & KP792990 & 99 \\
KIRL4 & Leaf & Streptomyces sp. N7 & KP792992 & 100 \\
\hline
\end{tabular}


In this study, the majority of active antagonistic actinomycetes against Xoc belonged to the Streptomyces strain isolated from the soils and the rhizosphere. A number of studies confirmed the abundance of Streptomyces as a dominant genus population in the soils and the rhizosphere (Shirokikh et al. 2006) and led to various studies on its antagonistic potential towards plant pathogens. Streptomyces are well-known as industrially useful compound producers and have drawn continuous attention in new bioactive compound screening derived from this genus. Previous studies proved that Streptomyces strains are capable of producing antibiotics and extracellular enzymes for biocontrol and plant growth-promoting activities (Inbar et al. 2005; Jog et al. 2012).

\section{Hydrolytic enzyme production and plant growth-promoting potential}

Actinomycete isolates that tested positive in the antimicrobial test against Xoc demonstrated positive reactions in different hydrolytic enzyme production tests (amylase, protease, lipase and cellulose). Isolates TKSB1, TKSC3 and SS8 showed positive reactions for all enzymes production. Isolates TKSC3 and SS8 were also positive and produced the highest result for antibacterial activity from the previous experiment. From 20 antagonistic actinomycete isolates, $85 \%$ produced at least one hydrolytic enzyme, and the remainder showed no hydrolytic enzyme production (isolates TKSB2, SL1 and KIRJ8). Indications for positive results of all enzyme production tests are shown in Table 4 . The screening results for PGP traits are depicted in Table 5. Only $30 \%$ of 20 antagonistic actinomycetes were positive in the phosphate solubilisation test, i.e., $65 \%$ for siderophore production, $30 \%$ for nitrogen fixation activity and $10 \%$ for hydrogen cyanide production. The IAA or phytohormone production was detected in all the potential actinomycete isolates with values ranging from 0.64 to $17.76 \mu \mathrm{g} / \mathrm{mL}$. Isolate TKSB5 showed the highest value for IAA production at 17.76 $\mu \mathrm{g} / \mathrm{mL}$. All the isolates demonstrated at least one trait of plant growth-promoting potential.

Table 4 - Production of hydrolytic enzyme by active antagonistic actinomycetes.

\begin{tabular}{|c|c|c|c|c|}
\hline \multirow[t]{2}{*}{ Isolate } & \multicolumn{4}{|c|}{ Positive reaction zone $(\mathrm{mm}){ }^{*}$} \\
\hline & Amylase & Protease & Lipase & Cellulase \\
\hline TKSB1 & $7.33 \pm 0.67^{\mathrm{cd}}$ & $9.67 \pm 0.86^{\mathrm{d}}$ & $14.83 \pm 0.17^{\mathrm{a}}$ & $7.33 \pm 1.20^{\mathrm{c}}$ \\
\hline TKSB2 & ND $* *$ & ND & ND & ND \\
\hline TKSB3 & ND & ND & $5.33 \pm 0.67^{\mathrm{fg}}$ & $1.67 \pm 0.33^{\mathrm{e}}$ \\
\hline TKSB4 & $3.33 \pm 0.88^{\mathrm{e}}$ & $1.50 \pm 0.29^{\mathrm{gh}}$ & ND & ND \\
\hline TKSB5 & $3.67 \pm 0.88^{\mathrm{e}}$ & $2.33 \pm 0.33^{\mathrm{fg}}$ & ND & ND \\
\hline TKSC3 & $15.00 \pm 1.00^{\mathrm{a}}$ & $0.67 \pm 0.17^{\text {gh }}$ & $10.83 \pm 0.44^{\mathrm{d}}$ & $8.67 \pm 1.20^{b}$ \\
\hline TKIRK1 & $9.33 \pm 1.67^{c}$ & ND & $12.00 \pm 1.04^{\mathrm{abcd}}$ & ND \\
\hline TKIRK4 & ND & $12.33 \pm 0.67^{\mathrm{c}}$ & $11.67 \pm 0.33^{\mathrm{bcd}}$ & ND \\
\hline TKIRK6 & ND & ND & $6.00 \pm 1.16^{\mathrm{fg}}$ & ND \\
\hline SRWP6 & ND & $18.33 \pm 2.19^{b}$ & $6.00 \pm 1.00^{\mathrm{fg}}$ & ND \\
\hline SS1 & ND & $25.67 \pm 0.88^{\mathrm{a}}$ & $14.00 \pm 2.65^{\mathrm{abc}}$ & $3.67 \pm 0.33^{\mathrm{d}}$ \\
\hline SS6 & $12.33 \pm 1.45^{b}$ & ND & $14.17 \pm 3.98^{\mathrm{ab}}$ & $7.67 \pm 0.67^{b c}$ \\
\hline SS8 & $13.83 \pm 0.73^{\mathrm{ab}}$ & $3.83 \pm 0.33^{\mathrm{ef}}$ & $11.17 \pm 0.60^{\mathrm{cd}}$ & $10.50 \pm 0.29^{a}$ \\
\hline SS9 & $6.00 \pm 1.53^{\mathrm{d}}$ & $1.83 \pm 0.17^{\text {fgh }}$ & ND & ND \\
\hline SL1 & ND & ND & ND & ND \\
\hline KU5 & ND & $5.00 \pm 0.00^{\mathrm{e}}$ & $9.67 \pm 0.33^{\mathrm{de}}$ & $6.67 \pm 0.67^{c}$ \\
\hline KSJ1 & ND & $3.83 \pm 1.59^{\mathrm{ef}}$ & ND & ND \\
\hline KSJ7 & ND & ND & $4.83 \pm 0.44^{f g}$ & ND \\
\hline KIRJ8 & ND & ND & ND & ND \\
\hline KIRL4 & $8.17 \pm 0.17^{\mathrm{c}}$ & ND & $7.33 \pm 0.33^{\text {ef }}$ & $3.00 \pm 0.29^{\mathrm{d}}$ \\
\hline
\end{tabular}

\footnotetext{
Average \pm standard error from triplicate samples. The means in column with the same letter are not significantly different (LSD $\alpha=0.05$ )

${ }^{* *} \mathrm{ND}$ - not detected
} 
Table 5 - Plant growth-promoting activities by active antagonistic actinomycetes.

$\begin{array}{cccccc}\text { Isolate } & \begin{array}{c}\text { Phosphate } \\ \text { solubilisation }(\mathrm{mm})\end{array} & \begin{array}{c}\text { Siderophore } \\ \text { production }(\mathbf{m m})\end{array} & \begin{array}{c}\text { Phytohormone } \\ \text { production }(\mu \mathrm{g} / \mathrm{mL})\end{array} & \begin{array}{c}\text { Nitrogen } \\ \text { fixation }\end{array} & \begin{array}{c}\text { Hydrogen } \\ \text { cyanide }\end{array}\end{array}$

\begin{tabular}{|c|c|c|c|c|c|}
\hline TKSB1 & $\mathrm{ND}^{* * * *}$ & ND & $2.99 \pm 0.22^{h i}$ & - & - \\
\hline TKSB2 & ND & ND & $0.64 \pm 0.17^{\mathrm{k}}$ & - & - \\
\hline TKSB3 & ND & ND & $1.13 \pm 0.11^{\mathrm{jk}}$ & - & - \\
\hline TKSB4 & $2.17 \pm 0.17^{b}$ & $16.00 \pm 0.58^{b}$ & $7.67 \pm 0.47^{\mathrm{de}}$ & + & - \\
\hline TKSB5 & ND & $29.67 \pm 1.86^{\mathrm{a}}$ & $17.76 \pm 1.02^{\mathrm{a}}$ & - & - \\
\hline TKSC3 & ND & $14.00 \pm 1.16^{b c}$ & $15.10 \pm 0.33^{b}$ & + & - \\
\hline TKIRK1 & ND & ND & $9.93 \pm 0.06^{c}$ & - & - \\
\hline TKIRK4 & ND & $8.00 \pm 0.00^{\mathrm{de}}$ & $4.44 \pm 0.90^{\mathrm{gh}}$ & - & \\
\hline TKIRK6 & $1.17 \pm 0.17^{\mathrm{c}}$ & ND & $14.17 \pm 0.58^{b}$ & + & - \\
\hline SRWP6 & $1.50 \pm 0.29^{c}$ & $4.67 \pm 0.33^{f}$ & $3.71 \pm 0.24^{\mathrm{hi}}$ & - & + \\
\hline SS1 & ND & $13.33 \pm 0.17^{c}$ & $3.94 \pm 0.22^{\mathrm{hi}}$ & - & + \\
\hline SS6 & ND & ND & $9.67 \pm 0.04^{b}$ & + & - \\
\hline SS8 & ND & $16.00 \pm 3.06^{b}$ & $8.91 \pm 0.05^{\mathrm{cd}}$ & - & - \\
\hline SS9 & ND & $9.50 \pm 0.58^{\mathrm{d}}$ & $3.72 \pm 0.20^{\mathrm{hi}}$ & + & - \\
\hline SL1 & ND & $5.67 \pm 1.20^{\mathrm{ef}}$ & $2.47 \pm 0.18^{\mathrm{ij}}$ & - & - \\
\hline KU5 & $2.17 \pm 0.60^{b}$ & $4.50 \pm 0.29^{f}$ & $0.54 \pm 0.02^{\mathrm{k}}$ & - & - \\
\hline KSJ1 & $2.83 \pm 0.17^{\mathrm{a}}$ & ND & $4.10 \pm 0.11^{h}$ & - & - \\
\hline KSJ7 & $0.0^{\mathrm{d}}$ & $0.0^{g}$ & $7.10 \pm 1.87^{\mathrm{ef}}$ & + & - \\
\hline KIRJ8 & $0.0^{\mathrm{d}}$ & $0.67 \pm 0.17^{\mathrm{g}}$ & $2.88 \pm 0.06^{\mathrm{hi}}$ & - & - \\
\hline KIRL4 & $2.83 \pm 0.17^{\mathrm{a}}$ & $13.33 \pm 0.88^{c}$ & $5.79 \pm 0.51^{\mathrm{fg}}$ & - & - \\
\hline
\end{tabular}

"Average \pm standard error from triplicate samples. The means in column with the same letter are not significantly different (LSD $\alpha=$ $0.05) .{ }_{* * *}^{*}+$ positive result and -: negative result for the respective test. Results were confirmed with triplicate samples. ${ }^{* * *} \mathrm{ND}-$ not detected.

Data from this study proved that the highest antiXoc pathogen activities not only displayed antagonistic activity characteristics but also tested positive for plant growth activity and hydrolytic enzyme production. The potential for development of actinomycetes as a biocontrol agent was primarily indicated by the antagonistic activities mechanism, which could act: a) directly via an antibiosis or lysis mechanism, or b) indirectly by inducing plant defences and growth promoter substances (Berg and Hallmann 2006). The antibiosis mechanism is facilitated by antibiotic compounds, and the lysis mechanisms are facilitated by amylase, protease, chitinase, cellulase and lipase enzymes produced by the actinomycetes. Additionally, such plant growthpromoting activities as indole acetic acid (IAA) production, siderophore production, phosphate solubilisation, hydrogen cyanide, ammonia production and nitrogen fixation characteristics indirectly aid in combating disease development.

Characterisation of novel biocontrol agents should not be highlighted by antagonistic activity alone because other characteristics (i.e., hydrolytic enzyme producers and plant growth promoters) are also important for a successful biocontrol agent.
Combination of hydrolytic enzymes or other antagonistic mechanisms result in a higher level of antagonism than that obtained from a single mechanism alone (Howell 1998). Preliminary assessments of these characteristics are important for the best selection of biocontrol agent candidates. From this study, active antagonistic actinomycetes were grouped by cluster analysis based on plant growth promoter and hydrolytic enzyme producer characteristics. Cluster 1 was represented by the Streptomyces strain that demonstrated the highest value and positive result for both hydrolytic and plant growth-promoting enzymes.

\section{Cluster analysis by Ward's Method (SAS) based on hydrolytic enzyme and plant growth- promoting analysis}

A cluster analysis was run on the sample scores (SAS version 9.3) using Proc Cluster and Ward's method to group the strains based on hydrolytic enzyme and plant growth-promoting traits. A dendrogram was created using the Proc Tree program. Semi-partial R-squared values showed three different clusters with branches splitting at 0.15 (Fig. 3). 


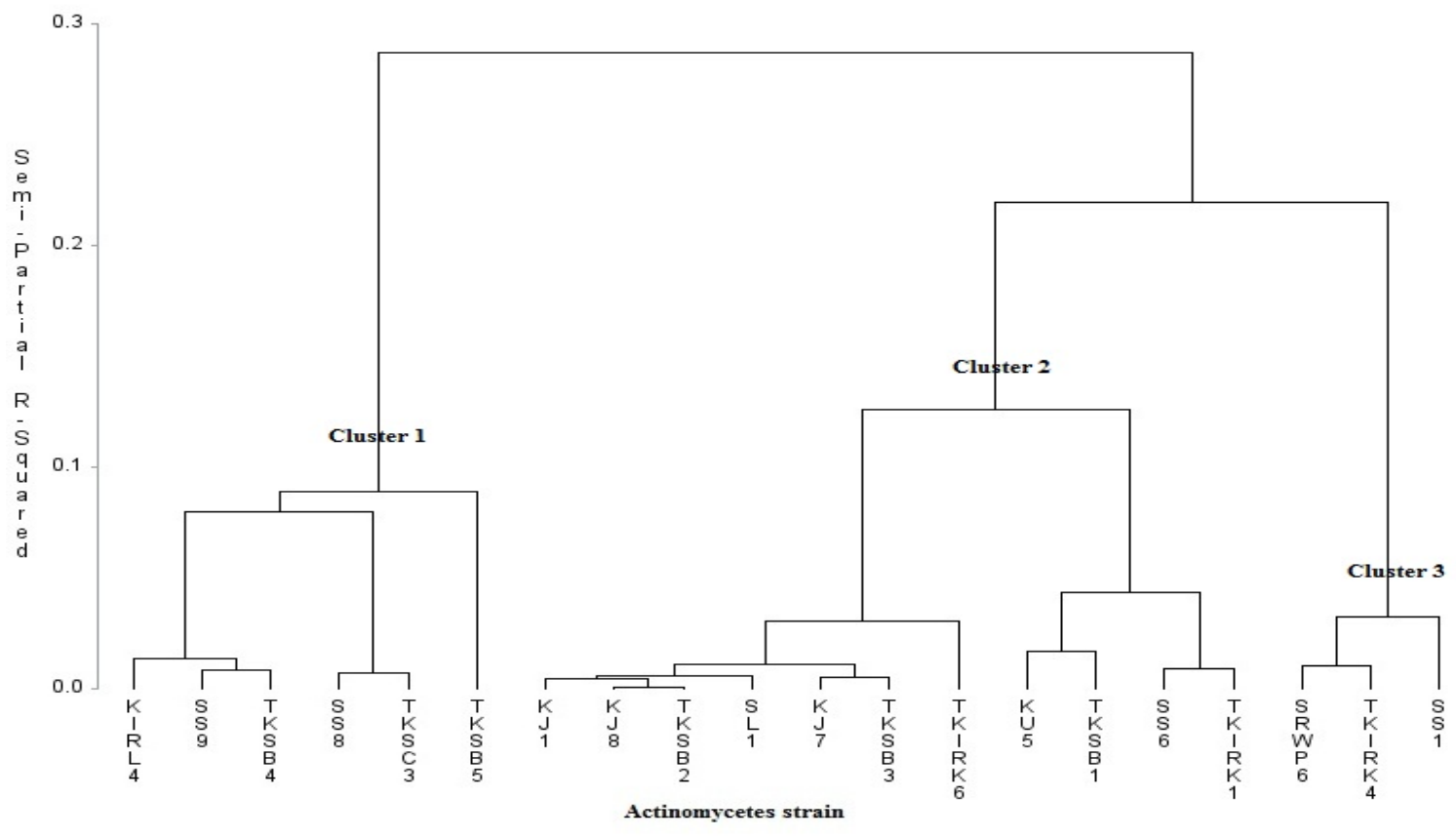

Figure 3 - Classification of different strains of actinomycetes based on hydrolytic enzyme and plant growth-promoting analysis. Cluster analysis using Ward's minimum variance was performed to assess the degree of similarity. Semi-partial R-squared values indicate the proportion of variance estimated for each of the nodes. For identities of strains, please refer to Table 3.

Cluster 1 was dominated by Streptomyces strains KIRL4 (Streptomyces sp. N7), SS9 (S. hygroscopicus), TKSB4 (Streptomyces sp. T1), SS8 (Streptomyces sp. SW4-2s), TKSC3 (S. shenzhenensis) and TKSB5 (S. koyangensis). The highest and strongest antagonistic activity of actinomycete strains (SS8, TKSC3, TKSB5 and SS9) based on in vitro assay tested against Xoc were grouped together in Cluster 1 in Figure 3, which proved that Streptomyces strains isolated from this study could be used as antibiotic and hydrolytic enzyme producers as well as plant growth promoters. Plant growth-promoting and biocontrol properties are both important traits in crop yield and production (Verma et al. 2011) and their beneficial attributes are largely dependent on their capability of producing secondary metabolites (Kunoh 2002). Thus, preliminary screening via in vitro assay is important as initial step in selecting the best actinomycetes with multi beneficial attributes as plant growth regulators and biocontrol agent properties.

\section{CONCLUSION}

This study is the first report to describe the in vitro activity of actinomycetes against the Xoc pathogen and in vitro screening for plant growth and hydrolytic enzyme traits of each potential strains. Preliminary analysis based on antibiotic activity, hydrolytic enzyme and plant growth hormone production facilitated the best selection of actinomycete candidates. Streptomyces were the most promising strains isolated from this study and further studies would be required to evaluate their potential as biocontrol and plant growth promoters under greenhouse and field conditions. Secondary metabolites that are responsible for the antagonistic effects will be further studied for a more comprehensive understanding.

\section{ACKNOWLEDGEMENTS}

The authors gratefully acknowledge financial support from the Long-Term Research Grant Scheme (Rice Research-5525001), Universiti 
Putra, Malaysia, as well as assistance and laboratory technical support from Mrs. Junaina Jaafar, Department of Plant Protection, Faculty of Agriculture, UPM.

\section{REFERENCES}

Aghighi S, Shadidi Bonjar GH, Rawashdeh R, Batayneh S, Saadoun I. First report of antifungal espectra of activity of Iranian actinomycetes strains against Alternaria solani, Alternaria alernata, Fusarium solani, Phytophthora megasperma, Verticillium dahliae, and Saccharomyces cerevisiae. Asian J Plant Sci. 2004; 3: 463-471.

Alexander M. Introduction to Soil Microbiology. 2. ed. New York: Wiley, 1997. p. 467.

Arasu MV, Duraipandiyan V, Agastian P, Ignacimuthu S. In vitro antimicrobial activity of Streptomyces spp. ERI-3 isolated from Western Ghats rock soil (India). J Mycol Med. 2009; 19: 22-28.

Baltz, RH. Renaissance in antibacterial discovery from actinomycetes. Curr Opin Pharmacol. 2008; 8: 557563.

Bentley SD, Chater KF, Cerdeno-Tarraga AM, Challis GL, Thomson NR, James K.D. Complete genome sequence of the model actinomycete Streptomyces coelicolor A3(2). Nature. 2002; 417: 141-147.

Berg G and Hallmann J. Control of plant pathogenic fungi with bacterial endophytes. In: Shculz BJE, Boyle CJC, Sieber TN, editor. Microbial root endophytes. Berlin Heidelberg: Springer-Verlag, 2006. p. 53-70.

Chen $\mathrm{CH}$, Zheng W, Huang XM, Zhang DP, Lin XH. Major QTL conferring resistance to rice bacterial leaf streak. Agricult Sci China. 2006;5(3): 216-220.

Doumbou CL, Hamby Salove MK, Crawford ET, Beaulieu C. Actinomycetes: promising tools to control plant diseases and to promote plant growth. Phytoprotection. 2001; 82: 85-102.

Dutta S, Singh RP, Jinda JK. Effect of antagonistic bacteria and plant defence activators on management of bacterial leaf spot of mungbean. Indian Phytopathol. 2005; 8: 269-275.

El-Tarabily KA, Sivasithamparam K. Nonstreptomycete actinomycetes as biocontrol agents of soil-borne fungal plant pathogens and as plant growth promoters. Soil Biol Biochem. 2006; 38: 1505-1520.

Garbeva P, van Elsas JD, van Veen JA. Rhizosphere microbial community and its response to plant species and soil history. Plant Soil. 2008; 302: 19-32.

Grayston R, Vaughan D, Jones D. Rhizosphere carbon flow in trees, in comparison with annual plants: the importance of root exudation and its impact on microbial activity and nutrient availability. Appl Soil Ecol. 1996; 5(1): 29-56.
Hamdali H, Hafidi EM, Virolle MJI, Ouhdouch EY. Rock phosphate-solubilizing actinomycetes: screening for plant growth-promoting activities. World Journal J Microbiol Biotechnol. 2008; 24: 2565-2575.

Hasegawa S, Meguro A, Shimizu M. Endophytic Actinomycetes and Their Interactions with Host Plants . Actinomycetologica. 2006; 20: 72-81.

Howell CR. The role of antibiosis in biocontrol. In: Harman GE, Kubicek CP, editor. Trichoderma \& Glioclad. Padstow: Taylor \& Francis, 1998. pp. 173184.

Inbar E, Green SJ, Hadar Y, Minz D. Competing factors of compost concentration and proximity to root affect the distribution of streptomycetes. Microb Ecol. 2005; 50: 73-81.

Jog R, Nareshkumar G, Rajkumar S. Plant growth promoting potential and soil enzyme production of the most abundant Streptomyces spp. from wheat rhizosphere. J Appl Microbiol. 2012; 113: 1154-1164.

Kaur T, Sharma D, Kaur A, Manhas RKP. Antagonistic and plant growth promoting activities of endophytic and soil actinomycetes. Arch Phytopathol Pflanzenschutz. 2013; 46(14): 1756-1768.

Kloepper JW, Ryu CM, Zhang SA. Induced systemic resistance and promotion of plant growth by Bacillus spp. Phytopathology. 2004; 94: 12591266.

Kunoh H. Endophytic actinomycetes: attractive biocontrol agents. J Gen Plant Pathol. 2002; 68: 249252.

Lemessa F, Zeller W. Screening rhizobacteria for biological control of Ralstonia solanacearum in Ethiopia. Biol Control. 2007; 42: 336-344.

Loqman S, Barka EEA, Clement CE, Ouhdouch EY. Antagonistic actinomycetes from Moroccan soil to control the grapevine gray mold. World Journal J Microbiol Biotechnol. 2009; 25: 81-91.

Lugtenberg B, Kamilova F. Plant-growth-promoting rhizobacteria. Апnu Rev Microbiol. 2009; 63: 541556.

Mahmoud ALE, Abd-Alla MH. Siderophore production by some microorganisms and their effect on Bradyrhizobium-mung bean symbiosis. Int J Agric Biol. 2001; 3(2): 157-162.

Naher UA, Radziah O, Shamsuddin ZH, Halimi MS, Mohd Razi I. Isolation of diazotrophs from different soils of Tanjung Karang rice growing area in Malaysia. Int J Agric Biol. 2009; 11: 547-552.

Oskay M. Antifungal and antibacterial compounds from Streptomyces strains. Afr J Biotechnol. 2009; 8(13): 3007-3017.

Ouhdouch Y, Barakate M, Finace C. Actinomycetes from Maroccan habitats: screening for antifungal activites. Eur J Soil Biol. 2001; 37: 69-74.

Saharan BS, Nehra V. Plant Growth promoting rhizobacteria: a critical reviews. Life Sci Med Res. 2011, LSMR-21: 1-30. 
Shirokikh IG, Zenova GM, Mersaeva OV, Lapigina EV, Lysak LV. Abundance and structure of actinomycete complexes in the rhizosphere of winter rye, oats, and red clover. Biol Bull. 2006; 33(4): 404-408.

Silfkin M. Tween 80 Opacity Test Responses of Various Candida Species. J Clin Microbiol. 2000; 38(12): 4626-4628.

Turner S, Pryer KM, Miao VPW, Palmer JD. Investigating deep phylogenetic relationships among cyanobacteria and plastids by small subunit rRNA sequence analysis. J Eukaryot Microbiol. 1999; 46: 327-338.

Velusamy P, Gnanamanickam SS. Identification of 2,4diacetylphloglucinol (DAPG) production by plantassociated bacteria and its role in suppression of rice bacterial blight in India. Curr Sci. 2003; 85: 12701273.
Verma, VC, Singh, SK, Prakash, S. Bio-control and plant growth promotion potential of siderophore producing endophytic Streptomyces from Azadirachta indica A. Juss. J Basic Microb. 2011; 51: 550-556.

Wang L, Makino S, Subedee A, Bogdanove AJ. Novel candidate virulence factors in rice pathogen Xanthomonas oryzae pv. oryzicola as revealed by mutational analysis. Am Soc Microb. 2007; 73: 80238028.

Xie, GL, Mew TW. A leaf inoculation method for detection of Xanthomonas oryzae pv. oryzicola from rice seed. Plant Dis. 1998; 82: 1007-1011.

Received: May 12, 2015; Accepted: July 26, 2015 